\title{
A Propósito das Noções de Resistência e Tomada de Posição na Análise de Discurso: movimentos de resistência nos processos de identificação com o ser paraguaio ${ }^{1}$
}

\author{
Regarding the Notions of Resistance and Taking Position at \\ DisCOURSE ANALYSIS: RESISTANCE MOVEMENTS AT THE IDENTIFICATIONS \\ WITH THE PARAGUAYAN
}

Fabiele Stockmans de Nardi* Felipe Augusto Santana do Nascimento**

Resumo: Este artigo propõe um retorno às noções de resistência e tomada de posição no âmbito da Análise de Discurso pecheuxtiana, mediante a observação de como a noção de sujeito foi reconfigurada no interior da própria teoria, permitindo uma abertura para se pensar a reproduçãotransformação da luta de classes. A consideração da contradição como inerente ao discurso e a interpelação do sujeito como um ritual sempre sujeito à falha

\footnotetext{
* Doutora em Teorias do Texto e do Discurso pela Universidade Federal do Rio Grande do Sul (2007). Professora do Programa de Pós-Graduação em Letras da Universidade Federal de Pernambuco. Contato: fabielestockmans@gmail.com.

** Mestre em Letras pela UFPE (2015). Doutorando em Linguística pela UNICAMP e bolsista CNPq. Contato: felipe.augustus@hotmail.com.

${ }^{1}$ Parte das discussões que ora trazemos pode ser observada em Nascimento (2013, 2015). Em relação a esses trabalhos, neste artigo, avançamos na discussão sobre a articulação entre as noções de resistência e tomada de posição, a ponto de afirmarmos, de maneira mais clara, que a resistência é concomitante aos processos de interpelação do indivíduo em sujeito do discurso, ou seja, é um elemento fundante no processo de interpelação. Além disso, no que se refere aos brasiguaios, observaremos que o discurso da pureza paraguaia funciona pelo movimento da desambiguização do termo "brasiguaios".
} 
permitem observar não apenas a sujeição a um discurso, mas os movimentos de transformação e resistência que são produzidos pelo sujeito a partir de sua inserção em determinada formação discursiva, fazendo-nos olhar para a heterogeneidade como inerente a esse espaço. Para pensar a relação entre resistência e tomadas de posição, analisamos uma série de enunciados que se vinculam à declaração do líder dos carperos do Paraguai, Eulálio Lopez, em que este nega a existência dos brasiguaios. Mediante a análise destes enunciados, procurar-se-á pontuar os movimentos de tomada de posição e resistência dos sujeitos a esses dizeres, discutindo a amplitude das noções de resistência e de tomada de posição na $\mathrm{AD}$ e sua produtividade na prática analítica.

Palavras-chave: Análise de discurso. Sujeito do discurso. Resistência.

Abstract: This article proposes a recurrence to the notions of resistance and taking position through the Pecheuxtian Discourse Analysis, by observing how the subject notion was reconfigured within the theory itself, allowing an opening to think the reproduction-transformation of class struggle. Assuming the contradiction as inherent to the discourse and the interpellation of the subject as a ritual always susceptible to fail, allow us to observe not only the subjection to a discourse, but also the movements of transformation and resistance produced by the subject from their inception in a defined discursive formation, helping us to look to the heterogeneity as inherent to this space. From the statement of the carperos leader of Paraguay, Eulálio Lopez, who refuses the existence of braziguayans, the research will point out the taking position movements and the resistance of the subject to these sayings, discuss the amplitude of notion of resistance and taking position at the Discourse Analysis and its productivity in analytical practice.

Keywords: Discourse Analysis. Discourse Subject. Resistance.

\section{Introdução}

A discussão em torno da noção de sujeito do discurso percorreu os trabalhos de Michel Pêcheux, ora em oposição a uma concepção de sujeito idealista/psicologizante - que controla e domina o seu dizer; ora em oposição a uma concepção materialista-homogeneizada do sujeito, que encobre sua 
dimensão histórica e simbólica. Na contramão dessas concepções dominantes na época, Pêcheux propõe articular a dimensão do inconsciente ao atravessamento ideológico, promovendo uma ruptura epistemológica com os saberes da época e posicionando-se politicamente frente às teorias vigentes.

O sujeito do discurso, ao contrário de confundir-se com o indivíduo, é uma posição no discurso; o indivíduo, então, afetado pelo inconsciente e interpelado pela ideologia, é convocado a ser sujeito e, portanto, a ocupar o seu lugar no emaranhado de discursos. A interpelação, assim, põe o sujeito diante do histórico e do simbólico e determina-o: ao regular o que pode e deve ser dito por meio da ilusão necessária do sujeito como origem de seu dizer (PÊCHEUX, 2009a).

A noção de Sujeito do Discurso, no entanto, nesse percurso teórico, foi alvo de críticas e também autocríticas feitas pelo próprio Pêcheux, cujos trabalhos - entre os quais podemos citar, de modo particular, Remontemos de Foucault a Spinoza $a^{2}(1980)$ e Só há causa daquilo que falha ou o Inverno politico francês: início de uma retificação (2009b) - marcam um deslocamento no modo como o sujeito do discurso vinha sendo teorizado. A homogeneização provocada pela ilusão de um ritual sem falhas produziu reformulações no projeto teórico pecheuxtiano. A partir delas passam a ter um papel essencial as noções de contradição e de falha no ritual, as quais puseram o sujeito do discurso diante da possibilidade de transformação e de resistência. O sujeito do discurso, dessa forma, não é apenas assujeitado a reproduzir as relações de produção dominante na luta de classes, mas pode transformá-las e também resistir ao discurso dominante, movimentos que provocam deslizamentos e até mesmo rupturas com a formação discursiva na qual se insere.

$\mathrm{Na}$ esteira das noções de resistência e tomada de posição, dedicaremos nosso trabalho a discutir os movimentos de resistência do sujeito no discurso a partir dos discursos que circularam contra a declaração do líder dos carperos ${ }^{3}$,

${ }^{2}$ Estamos usando, neste trabalho, a edição Mexicana da obra citada, embora já tenhamos disponível uma tradução em língua portuguesa: PÊCHEUX, M. Remontemos de Foucault a Spinoza. In. BARONAS, R. L. (Org.). Análise do discurso: apontamentos para uma história da noção-conceito de Formação Discursiva. Tradução de Maria do Rosário V. Gregolin. São Carlos: Pedro e João, 2011. p. 177-195.

${ }^{3}$ A palavra carperos (que usa carpas, isto é, tendas) é utilizada para designar o grupo dos sem-terra no Paraguai. 
Eulálio López, ao declarar, em fevereiro de 2012: “Os brasiguaios não existem para nós, apenas os paraguaios puros”. O fato teve ampla divulgação pela mídia paraguaia e brasileira, e um sentimento de revolta por parte dos brasiguaios, que se defenderam alegando: "somos demasiado paraguaios". Ao se inserir na rede de sentido do "somos demasiado paraguaios", o sujeito do discurso posiciona-se diante de discursos que (des)qualificam ${ }^{4}$ a população brasiguaia (e sua história) e produzem resistência a esses dizeres, resistência que perpassa os processos de identificação pelos quais os brasiguaios constroem a imagem do outro (as "vantagens" de ser brasileiro ou paraguaio) e de si (as "desvantagens" de ser brasiguaio).

No entanto, interrogamo-nos: que movimentos são esses de resistência que o sujeito do discurso provoca ao se identificar com o enunciado "Somos demasiado paraguaios" e suas paráfrases? Será que resistir aos discursos que colocam os brasiguaios à margem da sociedade paraguaia é necessariamente romper com esses mesmos dizeres? Analisar os movimentos de resistência do sujeito do discurso, por meio desse evento discursivo, ajuda-nos, portanto, a compreender os processos pelos quais o sujeito toma uma posição e resiste a outros dizeres.

\section{Das Primeiras Tentativas Teóricas a Semântica e Discurso: formação discursiva e tomada de posição}

A “máquina discursiva” proposta por Pêcheux em 1969, em Análise automática do discurso (1997), texto tido como fundador da teoria, traz consigo a proposição de um objeto, o discurso, que será analisado pelo “[...] 'processo discursivo', 'processo de produção do sentido"' (MALDIDIER, 2003, p. 22). Essa máquina, entretanto, "era uma máquina de abrir questões mais do que dar respostas” (MALDIDIER, 2003, p. 25) e, pouco a pouco, foi sendo posta em xeque pela consideração da heterogeneidade constitutiva de todo processo discursivo. Nesse trabalho de construção e desconstrução,

\footnotetext{
${ }^{4}$ Recorremos ao termo (des)qualificar, neste trabalho, para definir o movimento mediante o qual, pela negação da existência do brasiguaio, se reforça a sua impossibilidade de dizer-se cidadão, seja paraguaio ou brasileiro, e, portanto, requerer a proteção das leis desses países.
} 
destaca-se a "noção-conceito de formação discursiva", que vai incidir diretamente sobre o escopo da teoria pecheuxtiana: o discurso. O termo, emprestado de Foucault, aparece pela primeira vez na análise de discurso pecheuxtiana no ano de 1971, em um artigo em coautoria com Claudine Haroche e Paul Henry. Nesse texto, a formação discursiva é definida como "o que pode e deve ser dito (articulado sob a forma de uma arenga, de um sermão, de um panfleto, de uma exposição, de um programa, etc.) a partir de uma posição dada numa conjuntura dada" (HAROCHE; PÊCHEUX; HENRY, 2007, p. 26, grifos do original). Dessa forma, em relação a Foucault, Pêcheux desloca a noção de formação discursiva (FD) para pensá-la a partir da articulação entre uma perspectiva althusseriana da luta de classes e as contribuições da linguística saussuriana, acentuando as relações entre materialidade linguística, materialidade histórica e discurso.

É em Semântica e Discurso, contudo, que ele (re)ordena o pensamento que vinha desenvolvendo desde 1969 (PÊCHEUX, 2009a). O olhar de filósofo sobre a linguística toma como ponto de partida a semântica, lugar a partir do qual vai em busca de uma teoria do discurso (a semântica discursiva). Pêcheux trabalha com a FD em sua relação com o sujeito, pois "é através da relação do sujeito com a formação discursiva que se chega ao funcionamento do sujeito do discurso" (INDURSKY, 2007, p. 79).

Propõe que é por meio da forma-sujeito que o sujeito se inscreve em uma formação discursiva e nela se relaciona com os dizeres que lhe pertencem. Essa forma de inscrição obedece, a priori, a duas modalidades de tomada de posição do sujeito: a identificação e a contraidentificação. Na primeira, há a produção da evidência, da coincidência-reconhecimento do sujeito com o Sujeito (com "S" maiúsculo). Essa "tomada de posição" permite uma identificação plena do sujeito com os dizeres da formação discursiva na qual está inscrito. $\mathrm{Na}$ segunda, o sujeito não se relaciona completamente com o sujeito universal (o Sujeito com "S" maiúsculo) da formação discursiva e por meio de uma “'tomada de posição' que consiste, desta vez, em uma separação (distanciamento, dúvida, questionamento, contestação, revolta) com respeito ao que o 'sujeito universal' lhe 'dá a pensar" (PECHEUX, 2009a, p. 199, grifos do original), o sujeito se contraidentifica com os dizeres da FD em que está inserido. 
$\mathrm{Na}$ (ex)tensão entre a identificação plena e a contraidentificação, Pêcheux sugere uma terceira modalidade de tomada de posição, que "constitui um trabalho (transformação-descolamento) da forma sujeito e não sua pura e simples anulação" (PÊCHEUX, 2009a, p. 201-202, grifos do original). Há, portanto, uma desidentificação e um rompimento com a FD, na qual o sujeito estava inserido, e o consequente descolamento da forma sujeito com que se identificava, passando a se relacionar com uma outra formação discursiva. No entanto, apesar de o sujeito se desidentificar com uma formação discursiva, "a interpelação ideológica continua a funcionar, de certo modo, às avessas, isto é, contra e sobre si mesma, dando sustentação a uma nova prática" (GRIGOLETTTO, 2005, p. 64). Em suma, o sujeito continua a ser interpelado pela ideologia, mas em outra formação discursiva, sustentando e construindo outros dizeres.

Por meio dessas três modalidades de tomadas de posição propostas por Pêcheux, o sujeito do discurso pode reproduzir/transformar as relações de produção e os saberes a elas vinculados. Apesar da possibilidade de transformação e até mesmo rompimento com uma determinada FD, Pêcheux vai retificar o que ele mesmo designa como homogeneidade, que pressupunha o ritual da tomada de posição do sujeito do discurso em Semântica e discurso.

\section{Das Retificações à Resistência: a contradição e a falha no ritual}

Embora já esteja marcado em Semântica e Discurso o caráter indissociável dos movimentos de reprodução/transformação no seio das práticas sociais, permitindo olhar para a FD como um espaço aberto à heterogeneidade (DE NARDI, 2005), é a partir do texto apresentado no México, em 1977, Remontemos de Foucault a Spinoza (PÊCHEUX, 1980), que Pêcheux se propõe a observar de modo particular a categoria da contradição como constitutiva dos processos de subjetivação do sujeito.

En el caso particular de la religión, el TTP muestra que el 'axioma de la identidad' no se aplica al objeto ideología; toda la práctica de la lucha de clases en el terreno de la ideología viene a confirmarlo: una ideología no es idéntica a sí misma, no existe sino bajo la modalidad 
de la división, y no se realiza más que en la contradicción que con ella organiza la unidad y la lucha de los contrarios (PÊCHEUX, 1980, p. 192).

Ao ir de encontro com as teorias filosóficas vigentes na época ${ }^{5}$, por negarem o caráter político e encobrirem a luta de classes, Pêcheux, a partir de seu posicionamento político de "marxista-leninista, ligado às teses althusserianas, aproxima-se de Spinoza para fazer uma crítica à noção de formação discursiva tal como pensada por Foucault, um 'marxista-paralelo"' (GREGOLIN, 2006, p. 122), apontando justamente a impossibilidade de se tratar a contradição a partir do modo como a FD era vista pelo filósofo. Para ele, esse é um problema da teorização de Foucault sobre o conceito, ainda que reforce o enorme interesse de seu trabalho e das questões que propõe.

Por lo tanto, no se trata de deshacerse de Foucault acentuando aún más la inclinación reformista a la que puede llevar, sino de desarrollar la categoría marxista leninista de contradicción en el sentido de una apropiación mediante la teoría y la práctica del movimiento obrero, de lo materialista y revolucionario que contiene el trabajo de Foucault (PÊCHEUX, 1980, p. 194).

E justamente o que nos interessa nessa crítica é a importância dada por Pêcheux à ausência da categoria de ideologia e de contradição na luta de classes na obra Arqueologia do saber, de Foucault, visto queao trazer à baila a noção de contradição, Pêcheux vai mostrar que é por meio dela que é possível falar em reprodução-transformação, como propunha Althusser (1985) nos Aparelhos ideológicos do Estado (AIE). Para Gregolin (2006), Pêcheux (2006, p. 127) explicita, com isso, que "os aparelhos ideológicos são heterogêneos [e] os AIE não são puros instrumentos da ideologia dominante, mas resultado de uma intensa e contínua luta de classes". A transformação, dessa forma, só é possível porque a contradição se faz sentir no ato da reprodução. Da mesma forma

\footnotetext{
${ }^{5}$ Referimo-nos às correntes filosóficas designadas por Pêcheux como "logicismo", "historicismo" e "sociologismo" ou "risco da fala".
} 
que é por meio da contradição, inerente à luta de classes, que também podemos falar em uma "contradição no processo de identificação" (GREGOLIN, 2006, p. 128, grifos do original), pois o funcionamento da formação discursiva abriga a contradição e, com isso, diferentes possibilidades de tomada de posição do sujeito.

Mas é na retificação feita por Pêcheux, em 1978, acrescentada ao livro Semântica e discurso (PÊCHEUX, 2009a), que ele vai melhor evidenciar o lugar da resistência na teoria do discurso. Pelo viés do inconsciente, mostranos que pensar a "interpelação ideológica como ritual supõe reconhecer que não há ritual sem falhas” (PÊCHEUX, 2009b, p. 277, grifos do original). É, então, por meio da referência ao lapso e ao ato falho que ele suspeita de uma "origem não-detectável da resistência e da revolta" (PÊCHEUX, 2009b, p. 278) ${ }^{6}$. No entanto, é na "contradição histórica motriz (um se divide em dois) e não em um mundo unificado pelo poder de um mestre" (PÊCHEUX, 2009b, p. 179) que podemos falar em resistência, já que a disjunção ideológica se faz presente na luta de classes.

Ao ser interpelado em sujeito pela ideologia, o sujeito do discurso ocupa o seu lugar no emaranhado de discursos e, sempre-já sujeito, resiste. O

${ }^{6}$ Ventura (2009) propõe olhar o conceito de resistência na teoria psicanalítica de Freud pelo viés da teoria foucaultiana, a fim de ressignificar o que geralmente se entende por resistência na psicanálise e evidenciar uma aproximação entre os dois autores. Afirma que é predominante na psicanálise que o conceito de resistência esteja vinculado à ideia de conservação do mesmo, ou seja, a tudo aquilo que evita a mudança, mas defende que é possível entender a resistência, na esteira do pensamento de Foucault, como "uma força inventiva, móvel e produtiva na luta contra a submissão das subjetividades" (VENTURA, 2009, p. 154). Dessa forma, a resistência pode ser entendida "como meio de mudança, mas não como mudança em si" (VENTURA, 2009, p. 157), isto é, a resistência seria o movimento (paradoxal) necessário para a manutenção do mesmo e, ao mesmo tempo, deslocamento desse mesmo para o diferente. Estamos entendendo, assim como Ventura (2009), que também na teoria do discurso pecheuxtiana a resistência tem o estatuto de manutenção (ao levar o sujeito a reproduzir o "mesmo") ao mesmo tempo em que permite a instauração da diferença (ao impulsionar a transformação pela reprodução do "mesmo"). A resistência, assim, ao contrário de ser "oposição a" (LAGAZZI-RODRIGUES, 1998, p. 66), tem o estatuto de manutenção na $\mathrm{AD}$, já que é ela que permite a diferença necessária para que na reprodução se produza a transformação: o "mesmo", mas diferente. 
assujeitamento, ao contrário de significar submissão, é da ordem do político e do simbólico e, portanto, da resistência. O sujeito resiste a discursos outros ao ser interpelado em sujeito do discurso pela ideologia porque, para ser sujeito, é necessário ocupar uma posição no discurso e, portanto, resistir a outras. Eis o que entendemos como sendo um dos movimentos da resistência.

$\mathrm{O}$ assujeitamento, desse modo, pressupõe a resistência não como uma resposta à sujeição, mas como elemento fundante do processo. E para isso retomamos outra vez as palavras de Pêcheux (2009b, p. 279-280), que nos fala da contemporaneidade entre "revolta e extorsão do sobre-trabalho" e, em outro plano, entre a revolta e a linguagem, reafirmando que se essas categorias não se confundem, há uma inegável relação entre elas, ou, em suas palavras, "elas têm, politicamente, algo a ver uma com a outra". "Não há dominação sem resistência”, afirma Pêcheux no final de sua retificação de Só há causa daquilo que falha... (2009b, p. 281), porque todo ritual está sujeito à falha, e é justamente porque há falha no ritual e há a contradição da ordem da ideologia que podemos falar em resistência e em dominação, tomando-as como contemporâneas no sentido de que coexistem sem, no entanto, se confundir.

Assim, toda tomada de posição, toda identificação com uma forma sujeito implica resistência tanto a esse lugar como aos discursos outros que o atravessam, que contradizem os saberes dessa FD ou os negam, provocando rupturas. Desse mesmo modo, a tomada de posição do sujeito do discurso que o leva a se contraidentificar ou desidentificar também faz parte de um movimento de resistência, previsto no ritual (com falhas) e no trabalho de reprodução (resistência-revolta-revolução) transformação "da luta ideológica e política de classes" (PÊCHEUX, 2009b, p. 280)ㄱ, já que, nas palavras de Pêcheux (2011, p. 115):

No texto original de 1978, Só há falha daquilo que falha..., podemos inferir que, no processo de reprodução-transformação, está inserida a resistência-revolta-revolução (PÊCHEUX, 2009b, p. 280), movimentos necessários para que se saia da reprodução e se chegue à transformação. Esse caminho não é fácil, mas possível: de tanto o sujeito reproduzir o "mesmo", ele resiste, se revolta e produz a revolução que, por fim, provocará a transformação. Entendemos que a transformação só é possível porque há a resistência provocada tanto pela falha no ritual, quanto pela contradição, que permite, na reprodução do “mesmo", movimentos de resistência. 
... 'reprodução' nunca significou 'repetição do mesmo'. As proposições de Althusser sobre os Aparelhos Ideológicos do Estado, que procuram dar continuidade a determinadas colocações de Gramsci a respeito do conceito de hegemonia e da proximidade invisível do Estado no cotidiano, formam uma ajuda valiosa nessa direção, se ela for interpretada de tal forma que os processos de reprodução ideológicos também sejam abordados como local de resistência múltipla. Um local no qual surge o imprevisível contínuo, porque cada ritual ideológico continuamente se depara com rejeições e atos falhos de todos os tipos, que interrompem a perpetuação das reproduções.

Orlandi (2012, p. 213) afirma que "nos processos discursivos há sempre 'furos', falhas, incompletudes, apagamentos e isto nos serve de indícios/ vestígios para compreender os pontos de resistência" (p. 213) ${ }^{8}$. É na individu(aliza)ção do sujeito pelo Estado que a autora observa pontos de resistência, pois algo falha nesse processo e "a falha é o lugar do possível" (ORLANDI, 2012, p. 230). É na falha, continua Orlandi, que se abre espaço para a ruptura e se há a "condição para que os sujeitos e os sentidos possam ser outros, "fazendo sentido do interior do não-sentido"' (ORLANDI, 2012, p. 231). Este é um dos movimentos que a autora entende por resistência?.

${ }^{8}$ Em Só há causa daquilo que falha..., Pêcheux, ao criticar Foucault pelo seu "embaraço com respeito à psicanálise e ao marxismo" (2009b, p. 279), afirma que a teoria foucaultiana traz considerações importantes sobre as lutas revolucionárias, mas se "torna obscura, ficando inapreensíveis ospontos de resistência_e as bases da revolta de classe" (PÊCHEUX, 2009b, grifos nossos). Uma das preocupações de Pêcheux, por meio da retificação ao Semântica e discurso, é abrir um espaço teórico para as falhas e furos e, portanto, para a resistência.

9 Orlandi (2007a, 2007b, 2012) discute a noção do sujeito na Análise de discurso e os modos de individuação pelo Estado. Em seus trabalhos, questiona como se dá a resistência e, após problematizar esta questão, Orlandi (2012, p. 230) conclui que "podemos considerar que a questão da resistência está, de um lado, vinculada à relação entre forma-sujeito-histórica e a individuação pelo Estado; de outro, pelo processo de identificação do sujeito com a formação discursiva em sua vinculação ao interdiscurso" Ou seja, para a autora, é possível identificar dois movimentos de resistência: o primeiro na individuação pelo Estado e o segundo na identificação dos sujeitos com a formação discursiva. 
Arriscamo-nos a dizer que essa resistência provocada pela falha na interpelação do Estado é "uma forma de resistência entre outras" (ORLANDI, 2007a, p. 19), porque entendemos que a resistência é concomitante à interpelação do indivíduo em sujeito, uma vez que, como nos diz Pêcheux (1990), entender a interpelação como ritual implica assumir a impossibilidade de um ritual sem falhas. Interessa-nos, em especial, da discussão proposta pelo autor, a observação de que mesmo nos sutis movimentos de resistência que se mostram na relação do sujeito com a língua - nos jogos entre silenciar e calar, entre dizer para não dizer - reside a resistência, como um fantasma desse ritual sempre prestes a fazer ver suas rachaduras.

E através dessas quebras de rituais, destas transgressões de fronteiras: o frágil questionamento de uma origem, a partir da qual o lapso pode tornar-se discurso de rebelião, o ato falho, de motim e de insurreição: o movimento imprevisível em que uma série heterogênea de efeitos individuais entra em ressonância e produz um acontecimento bistórico, rompendo o círculo da repetição (PÊCHEUX, 1990, p. 17).

Então, se pensar no "sujeito do discurso implica a relação do simbólico com o político”, como afirma Orlandi (2007a, p. 11), não há sujeito que se constitua fora da resistência. Nessa relação, entre o simbólico e o político, o sujeito não pode estar livre de resistir: a resistência é a condição do ritual, nele há falhas porque há resistência. E a ideologia suporta a contradição: a reprodução(-resistência-)transformação.

\section{De(sa)fiando o Corpus}

Como já afirmamos anteriormente, o nosso corpus se refere ao evento discursivo da declaração do líder dos carperos do Paraguai, Eulálio López, sobre os brasiguaios não poderem ser considerados paraguaios, porque não são paraguaios puros. A esta declaração, seguiram-se discursos que se posicionavam em relação ao de Eulálio López. Limitamo-nos, neste trabalho, em mostrar as tomadas de posição do sujeito do discurso em relação aos dizeres que circulam em torno da declaração de López e como 
esse assujeitamento pressupõe um movimento de resistência do sujeito do discurso. Nesse sentido, faz-se necessário um rápido percurso histórico sobre a condição dos brasileiros no Paraguai.

A migração de brasileiros para o Paraguai iniciou-se ainda no século XIX, com o término da Guerra do Paraguai, mas foi na ditadura do General Alfredo Stroessner (1954-1989) que ela se fez com mais intensidade. Assim, foi na época das ditaduras paraguaia e brasileira que ambos os governos incentivaram o povoamento das regiões mais longínquas das grandes cidades, a fim de desenvolver os países. Nesse sentido, promoveram incentivos políticos para a industrialização de seus países: o Brasil incentivou a Marcha para o Oeste; o Paraguai, por sua vez, a Marcha para o Leste, e instituiu a Lei no 854 de 1963, que permitia o acúmulo de terras e sua venda/doação a estrangeiros. Além disso, as construções da hidrelétrica binacional de Itaipu e da Ponte da Amizade entre os dois países firmavam uma parceria entre eles e atraíam mais brasileiros para a região Leste do Paraguai.

No entanto, com o fim do crescimento econômico do Paraguai e, posteriormente, com o fim da ditadura de Stroessner, os brasileiros já não gozavam do mesmo prestígio, no Paraguai, e eram considerados um peso para a economia (WAGNER, 1990). Situação que se agravou, em 2005, quando a Lei no 2.532 de 2005 (Lei de segurança da fronteira do Paraguai) foi criada, proibindo a venda de terras na faixa de $50 \mathrm{~km}$ da fronteira a estrangeiros. É justamente nessas terras que a maioria dos brasiguaios (como são chamados os brasileiros que vivem no Paraguai) vive atualmente ${ }^{10}$. Em 2008, com a chegada de Fernando Lugo à presidência do país e com sua proposta de Reforma Agrária, a ocupação/invasão às terras de brasileiros e às de grandes proprietários, no Paraguai, se tornou frequente e é nesse contexto que o discurso do "paraguaio puro" insurge mais assiduamente.

\footnotetext{
${ }^{10}$ Wagner (1990) e Albuquerque (2005) compartilham o argumento de que o termo "brasiguaio" surgiu em uma conversa entre os líderes dos brasiguaios e o deputado federal sul mato-grossense Sérgio Cruz, na cidade de Mundo Novo no Mato Grosso do Sul, em 1985. No entanto, verificamos o uso da designação "brasiguaio" já em 1981, em uma reportagem da revista Veja: "Uma nação trilíngue: a terra dos brasiguaios que foram viver em solo paraguaio" (Uma nação trilingue, 1981, grifos nossos). Acreditamos, a partir dessa reportagem, que o termo já era recorrente no início dos anos 1980 .
} 
SD1: 'Brasiguayos' no existen para nosotros, o paraguayos o brasileños, sencillo es el tema', expresó Eulalio López. [...] El mismo indicó que 'el paraguayo puro es el que habla guaraní, usa la moneda nacional, entra en nuestras escuelas, levanta nuestras banderas. Ellos no, con el nombre de 'brasiguayos' usan nuestra cultura a su favor', agregó. [...] 'Los 'brasiguayos' no son puros, pero fundamentalmente por más que sea con mezcla es importante que se rijan a la ley paraguaya, respeten los simbolos y canten el Himno Nacional. Son residentes en Paraguay; los japoneses son residentes en Paraguay y los alemanes son residentes en Paraguay', sostuvo (ABC COLOR, 24/01/2012, grifos nossos).

SD2: Eulalio López negó que todo se trate de una actitud xenofóbica, sino que más bien constituye una 'defensa de la soberania del pais', que según dijo, está en manos de extranjerosy no de los paraguayos. 'Acá tenemos que pensar en recuperar lo que es del Paraguay. Estos colonos no respetan la ley fronteriza y nosotros creemos que hay paraguayos que merecen tener ese excedente de tierra que ahora sigue en manos de los productores', refirió (ÚLTIMAHORA.COM, 25/01/2012, grifos nossos).

Estamos entendendo que as sequências discursivas acima se filiam a uma FD que vamos designar "FD do nacionalismo dogmático paraguaio" (NASCIMENTO, 2015), pela vinculação dos saberes que regulam com a filosofia idealista do romantismo europeu e sua consolidação nos ideais republicanos do positivismo. Caracteriza-se pela volta ao passado, pela busca das raízes de um povo-origem, com o intuito de encontrar o que de mais essencial distingue essa nação de outras. No caso do Paraguai, o essencial da nação paraguaia é perpassado pela língua guarani, a língua falada pela maior parte da população, apesar da colonização espanhola ${ }^{11}$. Nesse sentido, em

${ }^{11}$ Rodríguez (2000), em sua tese de doutorado sobre o discurso construído sobre a língua guarani, observou que a preservação dessa língua, a língua do coração, é determinante para manutenção do discurso da pureza paraguaia. No entanto, "definir o Paraguai como nação bilíngüe, fixara identidade pela referência ao guarani, caracterizálo como lingua do coração, é algo que não corresponde à realidade (heterogênea) nacional [...]" (p. 242). 
SD1, um nosotros (nós) é quem tem o direito de categorizar quem pertence ou não à identidade paraguaia e, assim, o direito de excluir da nação paraguaia aqueles que são “diferentes". Ao contrário de incluir o outro, esse nosotros é excludente e trabalha em busca de uma homogeneidade paraguaia, em um movimento de resistência ao discurso da diferença, ao discurso da heterogeneidade. Mais do que isso: o discurso do nacionalismo paraguaio põe um fim na discussão sobre os brasiguaios - “'Brasiguayos' no existen para nosotros, o paraguayos o brasileños, sencillo es el tema" - ao pô-los em um local à margem. Os brasiguaios, para SD1, nunca poderão ser paraguaios, já que "el paraguayo puro es el que habla guaraní, usa la moneda nacional, entra en nuestras escuelas, levanta nuestras banderas". A ilusão de pureza, desejada por tantos outros povos, funciona como um mecanismo político de segregação do outro, um movimento de resistência do sujeito do discurso, tomado pela posição de identificação com essa "FD do nacionalismo dogmático paraguaio”, contra o estranho, a ameaça brasiguaia. É interessante perceber como essa ilusão da pureza se constrói por meio de um movimento de desambiguização ${ }^{12}$ do termo "brasiguaios" que aparece intercalado entre a afirmação de inexistência desses sujeitos e a decisão sobre a simplicidade do tema: tudo se resolve pelo uso da partícula disjuntiva, duplicada justamente para marcar a impossibilidade de uma coisa e outra, ou se é brasileiro ou se é paraguaio, não é possível pensar numa identidade entre lugares.

Ainda que antecipe no seu próprio dizer o questionamento sobre essa ilusão da pureza do ser paraguaio, abrindo espaço para admitir a "mezcla", o sujeito de SD1 situa os brasiguaios no lugar daqueles que não pertencem à nação porque não a respeitam: não se regem por suas leis, não respeitam seus símbolos, não cantam o hino nacional. São, como os japoneses ou alemães, "residentes". Contudo, eles são aqueles que "con el nombre de 'brasiguayos' usan nuestra cultura a su favor”. Paraguaios (puros) - lingua guarani - cultura paraguaia são, portanto, postos em uma relação de igualdade: ser paraguaio significa, portanto, falar o guarani e respeitar a cultura paraguaia (que parte da cultura paraguaia?). Já em SD2, essa “defensa de la soberanía

\footnotetext{
${ }^{12}$ Remetemos aqui à discussão proposta por Leandro Ferreira (2000) acerca da ambiguidade.
} 
del país" se constitui como uma tentativa de resgatar o Paraguai "de las manos de los extranjeros", "estos colonos", o outro ao qual se deve rechaçar - apesar de não se tratar de uma "actitud xenófoba". Atualiza-se, na construção do outro, a designação dos estrangeiros como "colonos", que tanto pode remeter àquele que trabalha na terra (o lavrador) ou à imagem do colonizador, que se apropriou da terra e se tornou grande proprietário. Os paraguaios são os que devem ter o "excedente" de terras, que legalmente estão asseguradas pela "lei da fronteira do Paraguai", e não os grandes proprietários.

SD3: 'Eu acho que a gente é tudo paraguaio. A gente já se sente parte da terra. Nunca passou pela minha cabeça deixar esse país', diz Rosenei, pai das jovens Victória, de 11 anos, e Cyntia, de 14. As meninas já representam a terceira geração dos descendentes de brasileiros no país (GASPARIN, 24/03/2012, grifos nossos).

SD4: 'Já somos demasiados paraguaios aqui, e também não falamos português, por isso não se fala de nós. Mas, se forem analisar, somos parte dos "brasiguaios", diz o agricultor paraguaio Ewald Loblein, de 46 anos, que é filho de gaúcho e proprietário de aproximadamente 600 hectares de terra. O pai do agricultor tinha apenas dez anos e já cresceu no país, por isso, não foi mantido o português como idioma. 'Não mantivemos os costumes do Brasil [...]. Não nego, meu pai é nascido no Brasil e tudo, mas já se passaram muitos anos, somo muito paraguaios', ressalta Loblein (GASPARIN, 25/03/2012, grifos nossos).

Ao contrário de SD1 e SD2, nas sequências SD3 e SD4 são questionados os saberes da "FD do nacionalismo dogmático paraguaio". Há uma tomada de posição que ocasiona uma "separação (distanciamento, dúvida, questionamento, contestação, revolta)" (PÊCHEUX, 2009a, p. 199, grifos do original) do sujeito do discurso com a forma sujeito dessa FD. Protestase com relação à ideia de um ideal de paraguaio, porque "a gente é tudo paraguaio". Nessa posição-sujeito de contraidentificação diante da forma sujeito dessa formação discursiva, o "a gente" (o outro, os considerados não paraguaios) "já se sente parte da terra”. Apesar de não terem todos os atributos de um "paraguaio puro", de alguns não terem nascido no Paraguai, eles 
“defendem" e não pensam em "deixar o país". Eles têm amor à nação paraguaia, já são "demasiado paraguaios"13 , pois muitos não mantiveram os costumes do Brasil e já não falam a língua portuguesa. O pertencimento à terra paraguaia, a adoção dos costumes paraguaios e a negação da língua portuguesa aparecem tanto como um movimento de resistência diante do discurso de que os brasiguaios não são paraguaios, como de filiação a esses mesmos discursos, já que esses sujeitos, ao se definirem paraguaios, o fazem por meio do amor à terra paraguaia. Eles se filiam à "FD do nacionalismo dogmático paraguaio" em uma tomada de posição de contraidentificação com os discursos dessa formação discursiva. Os sujeitos questionam os saberes da "FD do nacionalismo dogmático paraguaio", resistem a eles e assumem uma posição-sujeito distinta da observada anteriormente, mas não chegam a romper com essa FD, já que o respeito aos símbolos e à história paraguaia é uma constante. Eles não se enxergam como brasileiros, tampouco como brasiguaios, são paraguaios e não se reconhecem fora da nação paraguaia.

SD5: Independientemente a lo pautado por la Constitución Nacional, nadie en el Paraguay podría adjudicarse derechos de linaje (ver artículo: 'Todos somos extranjeros'. ABC, enero de 2011), pues sería tarea inútil intentar establecer diferencias con base en nuestra procedencia. Especialmente porque los limitados y esporádicos contingentes migratorios radicados en el Paraguay en siglos pasados se han aclimatado o 'paraguayizado' tan rápidamente que han sido los gestores de nuestra cultura, pioneros de nuestras empresas, protagonistas esenciales de nuestras actividades deportivas, y sus descendientes hasta dieron la vida por la patria (RUBIANI, 08/02/2012).

${ }^{13}$ É interessante perceber a força desse "demasiado" que se interpõe em um movimento de intensificação desse pertencimento. Se pode pensar que o efeito desse discurso é um dizer-se muito paraguaio, excessivamente paraguaio para que alguém lhe negue esse direito de pertencimento. A organização sintática do enunciado coloca o "demasiado" na posição de um advérbio que exige um olhar para esse lugar do excesso: não se trata de ser paraguaio somente, mas de o ser excessivamente, em um impossível pensar-se em outro lugar. 
SD6: 'Yo quiero seguir siendo paraguaya.' [...] Los brasileros no tienen responsabilidad de haber adquirido tierras dentro de los límites de frontera no permitidos por la Constitución, ni de bien usar los recursos naturales que lastimosamente nuestra gente no supo aprovechar, ni de crear fuentes de trabajo para nuestros compatriotas rurales (por llamarlos de alguna manera) en su mayoría tan tristemente carentes de capacitación. Pero si nosotros mismos, nos acostumbramos a usar ese término 'brasiguayos' ¿Será que no estamos dando pie a que en 20 años o menos se quieran independizar y formen Brasiguay y Paraguay como pasó con Checoslovaquia? Ellos siempre se diferenciaron y al checo le molestaba el eslovaco, y vice-versa. Pueden vivir en Paraguay, pueden serparaguayos o brasileros, o tener ambas nacionalidades. Pero aunque esté casada con uno de 'ellos', no me gusta esa palabra y mucho menos la forma en que se va arraigando (ABC COLOR, 13/03/2012).

SD7: 'Acá estamos en un gran dilema, estamos creando una Franja de Gaza. Si nos vamos a Brasil, nos llaman 'brasiguayos', ahora si estamos acá nos llaman brasileños, entonces no tenemos máspatria, y tenemos que formar como en la Franja de Gaza', señala el productor. [...] 'Hace 32 años estoy acá y tengo cuatro hijos paraguayos. Desmotiva, y los hijos de los inmigrantes de los paraguayos van perdiendo el amor por la patria, porque prácticamente dicen por ellos que no son paraguayos', indicó a Radio Cardinal (ABC COLOR, 27/03/2012, grifos nossos).

O discurso sobre o nacionalismo paraguaio vai adquirindo outros sentidos nas sequências acima, o que nos leva a afirmar que não se trata mais da "FD do nacionalismo dogmático paraguaio", mas de outra FD, que permite que outros efeitos de sentido irrompam e se atualizem. Aparentemente, as sequências SD5, SD6 e SD7 não são diferentes das anteriores, mas, discursivamente, elas provocam deslocamentos-rupturas nos saberes da "FD do nacionalismo dogmático paraguaio". A essa formação discursiva, a designaremos de "FD do direito de ser cidadão (brasileiro e/ou paraguaio)" uma vez que está em jogo não apenas o reconhecimento de ser ou não um paraguaio puro, mas o de ser reconhecido pelo Estado como cidadão: seja cidadão paraguaio, seja como cidadão brasileiro. Dessa 
forma, põe-se em xeque o "direito de linhagem", porque são "todos estrangeiros" e se "aparaguaizaram" ao longo do tempo, apesar da Constituição Nacional parecer fazer uma distinção. E é essa distinção que está em jogo nessa outra FD, já que se busca o reconhecimento legal do direito de ser cidadão paraguaio e/ou brasileiro. Os argumentos de que os estrangeiros ajudaram a desenvolver a cultura e "deram a vida pela pátria" funcionam em um posicionamento de resistência frente aos saberes da "FD do nacionalismo dogmático paraguaio".

É em SD6, portanto, que observamos que não se trata mais de um nacionalismo paraguaio, mas da busca pelo reconhecimento à cidadania paraguaia, que não necessariamente é perpassada por questões nacionais. Em SD6, ocupando a posição social de paraguaia, o sujeito resiste aos discursos que a põe na condição de não paraguaia, por ser casada com um brasileiro. "Eu quero seguir sendo paraguaia" é o desejo do sujeito-paraguaio, em SD6, e o desejo de muitos outros habitantes do Paraguai que não têm direito à cidadania paraguaia. Nesse sentido, é questionada a designação "brasiguaios" e as consequências de seu uso, já que ela pode gerar um movimento separatista e a criação de um país distinto do Paraguai, o "Brasiguai”, como já ocorreu em outros países, a exemplo da Checoslováquia. Assujeitado aos saberes da "FD do direito de ser cidadão (paraguaio/brasileiro)", o sujeito resiste ao discurso de um nacionalismo dogmático que, a partir de um "nós”, determina aqueles que podem (e os que não podem) fazer parte do Paraguai.

Em SD7, àqueles a quem é negado o direito de ser cidadão resta criar uma "Faixa de Gaza" e viverem sem pátria. Nesse entre-lugar, os sujeitos são levados a resistirem aos discursos de um nacionalismo paraguaio mais extremo e a buscarem um lugar para se reconhecerem cidadãos. Para esse grupo social, não há vantagem em ser de naturalidade brasileira ou paraguaia, porque eles são apenas os brasiguaios e, dessa forma, não têm direito nem de ser cidadão paraguaio, nem tampouco de ser cidadão brasileiro. Nessa outra FD, falando de outra posição, os sujeitos não são interpelados por uma "FD do nacionalismo dogmático paraguaio”, pois nela não há mais espaço para eles: foram relegados a não fazer parte nem da pátria brasileira, nem da paraguaia. "Desmotivados" e "perdendo o amor pela pátria", os sujeitos reproduzem os discursos do não pertencimento, da negação do direito de ser cidadão, mas a estes discursos resistem e, talvez, sejam levados a transformá-lo. 


\section{Na Tentativa de um Ponto Final}

As noções de resistência e tomada de posição do sujeito do discurso permearam nossa discussão ao longo dessa sucinta reflexão. No entanto, muito ainda precisa ser discutido e aprimorado na discussão sobre essas noções, que se mostram tão caras à $\mathrm{AD}$. O próprio Pêcheux, ao longo de suas reflexões sobre o sujeito do discurso, foi levado a reordenar o seu pensamento e a propor deslocamentos para assim comportar a falha constitutiva de todo ritual. Por meio das retificações propostas por Pêcheux, foi possível distanciar-se de uma concepção mais homogeneizada das modalidades de tomada de posição do sujeito do discurso e abrir espaço para uma reflexão sobre a noção de resistência na teoria do discurso.

A partir, então, das materialidades aqui analisadas, observamos que duas formações discursivas coexistem regulando os discursos acerca do ser paraguaio, as quais designamos de "FD do nacionalismo dogmático paraguaio" e "FD do direito de ser cidadão (brasileiro e/ou paraguaio)". Assujeitados à primeira formação discursiva, os sujeitos são levados a determinar um estereótipo de paraguaio puro e vinculá-lo à língua guarani, aos símbolos nacionais e à cultura paraguaia. Nesse lugar, observamos que o sujeito toma a posição de identificar-se "plenamente" com o discurso de um nacionalismo mais dogmático ou de contraidentificar-se a ele, já que não se enquadra no estereótipo de paraguaio puro, mas apresenta características que o vinculam a essa FD: respeita os símbolos nacionais e a cultura paraguaia e, mesmo fazendo parte dos brasiguaios, se reconhece paraguaio, defende o Paraguai como sua pátria e acredita ter esse direito legitimado socialmente. Mesmo não se identificando "plenamente" com os saberes da "FD do nacionalismo dogmático paraguaio", a resistência produzida por esses sujeitos em relação a eles se dá em um movimento que não é o da desidentificação com essa FD, mas a da construção de uma nova posição sujeito em que possam se acomodar, resistindo ao que lhes rechaça a fim de permanecer no grupo daqueles que são considerados paraguaios. Eles, portanto, reproduzem os saberes de que o paraguaio deve defender a pátria e respeitar seus símbolos, mas resistem ao discurso de um estereótipo de paraguaio fundado sobre a sua pureza e, assim, em contato com outros saberes, esses dizeres vão provocando deslocamentos dentro da própria FD. 
Por outro lado, há aquele grupo que também deseja ser reconhecido como paraguaio, mas que é posto à margem da sociedade paraguaia e vive como se estivesse em uma "Faixa de Gaza". Esse grupo é composto não só dos chamados brasiguaios, mas também por pessoas de naturalidade paraguaia que, por terem vínculo com os brasiguaios, são considerados parte "deles" e não parte do "nós", que dita quem são os verdadeiros paraguaios. Esses sujeitos, tomando uma posição em uma formação discursiva diferente da "FD do nacionalismo dogmático paraguaio", resistem aos saberes desta FD e se assujeitam a uma outra formação discursiva, em um movimento de resistência ao discurso de que não são paraguaios. Essa resistência perpassa a imagem que os brasiguaios constroem sobre o ser brasileiro e/ou o ser paraguaio, ou seja, das vantagens de ser cidadão de um desses países e as desvantagens de viver à margem, sem direitos políticos, como se fora a Faixa de Gaza.

Enfim, a resistência é concomitante ao processo de interpelação do indivíduo em sujeito do discurso, sendo esse processo necessário para que haja a transformação das práticas e a instituição de novos sentidos. Resta-nos saber, no entanto, quando a resistência realmente produz a transformação, pois nos parece que a resistência não é necessariamente um movimento que leva sempre à ruptura. Ao contrário, a resistência só pode levar à transformação quando ela cria um nó, isto é, um "ponto de resistência". Entendemos que esse "ponto de resistência" é o responsável pela transformação, pois "algo trava" no ritual e esse "algo que trava" é o responsável pelo fato de que o "mesmo" (a reprodução) possa levar à revolta-revolução-transformação. Talvez, seria o caso de pensarmos em modos de resistência que pudessem nos levar a considerar variações que iriam de uma resistência constitutiva ao processo de assujeitamento, necessário para a manutenção do "mesmo" (a tomada de posição de identificação), a uma resistência que "permite" a mudança e o contato com o diferente ( $\mathrm{da}$ ordem da tomada de posição de contraidentificação e desidentificação). 


\section{Referências}

ABC COLOR. Eulalio López: “Los 'brasiguayos' no existen para nosotros, solo los paraguayos puros’. Asunción, Paraguay, 24 ene. 2012. Disponível em: <http://bit.do/cWx4z>. Acesso em: 13 jan. 2015.

ABC COLOR. Yo quiero seguir siendo paraguaya. Asunción, Paraguay, 13 mar. 2012. Disponível em: <http://bit.do/cWzUj>. Acesso em: 13 jan. 2015.

ABC COLOR. Una Franja de Gaza en Paraguay. Asunción, Paraguay, 27 mar. 2012. Disponível em: <http://bit.do/cWzUu>. Acesso em: 13 jan. 2015.

ALBUQUERQUE. J. L. C. Fronteiras em movimento e identidades nacionais: a imigração brasileira no Paraguai. 2005. Tese (Doutorado em Sociologia) Universidade Federal do Ceará, Fortaleza.

ALTHUSSER, L. Aparelhos ideológicos de Estado. 2. ed. Tradução de Valter José Evangelista e Maria Laura Viveiros de Castro. Rio de Janeiro: Graal, 1985.

DE NARDI, F. S. Identidade, memória e os modos de subjetivação. In: INDURSKY, F.; LEANDRO FERREIRA, M. C. (Org.). Michel Pêcheux e a Análise do Discurso: uma relação de nunca acabar. São Carlos: Claraluz, 2005. p. 157-166.

GASPARIN, G. Filho de 'brasiguaio', agrônomo não pensa em viver no Brasil. Globo Rural, 24 mar. 2012. Disponível em: < http://bit.do/cWzSt>. Acesso em: 13 jan. 2015.

GASPARIN, G. 'Somos demasiado paraguaios', diz agricultor 'brasiguaio'. Globo Rural, 25 mar. 2012b. Disponível em: < http://bit.do/cWzST>. Acesso em: 13 jan. 2015.

GREGOLIN, M. R. Pêcheux e Foucault na análise de discurso: diálogos \& duelos. 2. ed. São Carlos: Claraluz, 2006. 
GRIGOLETTTO, E. A noção de sujeito em Pêcheux: uma reflexão acerca do movimento de desidentificação. Revista da língua(gem), Vitória da Conquista, n. 1, p. 61-67, jun. 2005.

HAROCHE, C.; PÊCHEUX, M.; HENRY, P. A semântica e o corte saussuriano: língua, linguagem, discurso. In: BARONAS, R. L. (Org.). Análise do discurso: apontamentos para uma história da noção-conceito de formação discursiva. São Carlos, SP: Pedro \& João, 2007 [1971]. p. 13-32.

INDURSKY, F. Da interpelação à falha no ritual: a trajetória teórica da noção de formação discursiva. In: BARONAS, R. L. (Org.). Análise do discurso: apontamentos para uma história da noção-conceito de formação discursiva. São Carlos, SP: Pedro \& João Editores, 2007, p. 75-88.

LAGAZZI-RODRIGUES, S. A discussão do sujeito no movimento do discurso. 1998. Tese (Doutorado em Linguística) - Universidade Estadual de Campinas, Campinas.

LEANDRO FERREIRA, M. C. Da ambigüidade ao equivoco: a resistência da língua nos limites da sintaxe. Porto Alegre: Editora da UFRGS, 2000.

MALDIDIER, D. A inquietação do discurso: (re)ler Michel Pêcheux hoje. Tradução de Eni P. Orlandi. Campinas: Pontes, 2003.

NASCIMENTO, F. A. S. Nas teias do sujeito do discurso: movimentos de resistência nos processos de identificação dos brasiguaios com o ser paraguaio. In: SEMINÁRIO DE ESTUDOS EM ANÁLISE DE DISCURSO - SEAD, 6., 2013, Porto Alegre. Anais... Porto Alegre: UFRGS, 2013. p. 1-7.

NASCIMENTO, F. A. S. Entre as fronteiras da "Terra prometida": os trabalhos da memória e da história na representação dos brasiguaios. 2015. Dissertação (Mestrado em Letras) - Universidade Federal de Pernambuco, Recife.

ORLANDI, E. P. O sujeito discursivo contemporâneo: um exemplo. In: INDURSKY, F.; LEANDRO FERREIRA, M. C. (Org.). Análise do discurso no Brasil: mapeando conceitos, confrontando limites. São Carlos: Claraluz, 2007a. p. 11-20. 
ORLANDI, E. P. A questão do assujeitamento: um caso de determinação histórica. ComCiência, v. 89, p. 2, 2007 b.

ORLANDI, E. P. Discurso e texto: formulação e circulação dos sentidos. 4. ed. Campinas: Pontes, 2012.

PÊCHEUX, M. Remontémonos de Foucault a Spinoza. In: TOLEDO, M. M. (Coord.) El discurso político. México, DF: Nueva Imagen;

Universidad Nacional de México, 1980 [1977]. p. 181-197.

PÊCHEUX, M. Delimitações, inversões, deslocamentos. Cadernos de Estudos Lingüisticos, Campinas, v. 19, p. 7-24, jul./dez. 1990 [1982].

PÊCHEUX, M. Análise automática do discurso. In: GADET, F; HAK, T. (Org.). Por uma análise automática do discurso. 3. ed. Campinas: Editora da Unicamp, 1997 [1969].

PÊCHEUX, M. Semântica e discurso: uma crítica à afirmação do óbvio. Tradução de Eni P. Orlandi et al. 4. ed. Campinas, SP: Editora da Unicamp, 2009 [1975].

PÊCHEUX, M. Só há causa daquilo que falha ou o inverno político francês: início de uma retificação. In: PÊCHEUX, M. Semântica e discurso. Tradução de Eni P. Orlandi et al. 4. ed. Campinas, SP: Editora da Unicamp, 2009b [1978]. p. 269-281.

PECHEUX, M. Ideologia: aprisionamento ou campo paradoxal? In: PÊCHEUX, M. Análise de Discurso. Michel Pêcheux. Textos Escolhidos por Eni Orlandi. Campinas: Pontes, 2011 [1982]. p. 107-130.

RODRÍGUEZ, C. M. Lingua, nação e nacionalismo: um estudo sobre o guarani no Paraguai. 2000. Tese (Doutorado em Linguística) Universidade Estadual de Campinas, Campinas.

RUBIANI, J. El Dr. Francia era "brasiguayo". ABC Color, Asunción, Paraguay, 08 feb. 2012. Disponível em: <http://bit.do/cWzTu>. Acesso em: 13 jan. 2015. 
ULTIMAHORA.COM. "Los hijos de los colonos no son paraguayos puros". Asunción, Paraguay, 25 ene. 2012. Disponível em: <http:// bit.do/cWx6e>. Acesso em: 13 jan. 2015.

UMA NAÇÃO trilíngue. Revista Veja, São Paulo, ed. 694, p. 48-49, 23 dez. 1981. Disponível em: <http://bit.do/cWxKb>.

VENTURA, R. Os paradoxos do conceito de resistência: do mesmo à diferença. Revista de Estudos de Psicanálise, Aracaju, n. 32, p. 153-162, nov. 2009.

WAGNER. C. Brasiguaios: homens sem pátria. Petrópolis: Vozes, 1990.

Recebido em: 30/05/2015

Aceito: $25 / 09 / 2015$ 